\title{
Het vaccin anno 1796
}

\section{Een ziekte bestrijden met iets dat die ziekte lijkt te veroorzaken? In het laatste decennium van de achttiende eeuw was dit een eigenaardige opvatting. Eerst kwam homeopathie, van dubieuze waarde. Maar kort daarna het eerste vaccin.}

\section{Auteur}

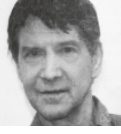

Dr. Frank Heynick (New York) is onder andere medisch-dentaal historicus. Alvorens in Groningen

tot doctor in de geneeskunde te promoveren, studeerde hij industriële vormgeving, geschiedenis, taalwetenschap en psychologie.
Terecht betreurde laat in de achttiende eeuw de Duitse arts dr. Samuel Hahnemann die situatie in de geneeskunde. Zijn weledelzeergeleerde collega's dienden hoge doses gevaarlijke krachtige stoffen toe van dubieuze effectiviteit, zoals kwik en opium. Hahnemann noemde deze aanpak, die toen al tweeduizend jaar bestond, contraria contrariis curantur: iets wordt door het tegenovergestelde genezen.

Door een proefje rond 1790 kwam Hahnesimilia similibus curentur: iets wordt genezen door iets dat daarop lijkt. Hij en zijn aanhangers begonnen (in gezonde toestand) een eindeloze reeks stoffen te slikken en noteerden de respectieve lichamelijke (en psychische) reacties. Deze stoffen zouden als geneesmiddelen dienen voor de ziekten met de corresmann aan een mogelijk alternatieve aanpak: ponderende symptomen. Hahnemanns redenering was dat door het kunstmatig opwekken van dezelfde symptomen als die van de ziekte zelf - van verkoudheid tot kanker tot depressie - het lichaam dubbel gestimuleerd wordt om die ziekte te bestrijden.

\section{BRAAKNOOT}

Interessant voor ons is dat Hahnemann drie soorten kiespijn onderscheidde en op basis van zijn proeven daarmee corresponderende middelen voorschreef. Chamomilla voor een hevige aanval 's nachts. Pulsatilla voor een stekende kiespijn die de zenuw aanspant. De braaknoot nux vomica voor een borende kiespijn.

Hahnemann noemde zijn nieuwe leer homeopathie. Hij zag het - terecht - als een zegen voor zijn patiënten, die nu gespaard werden voor de massale tegenaanvallen op de ziektes van zijn reguliere collega's.

Maar wacht even, zou je zeggen. Nux vomica zit vol strychnine, een uiterst dodelijk gif. Ah, maar Hahnemann had nóg een beginsel: het verdunnen van het middel totdat er maar één of twee moleculen van (bijvoorbeeld) nux vomica overblijft - of zelfs geen enkele molecuul. Bij het verdunnen schudde Hahnemann

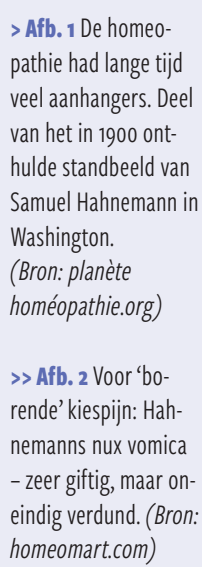

>Afb. 1 De homeopathie had lange tijd veel aanhangers. Deet hulde standbeeld van Samuel Hahnemann in Washington. (Bron: planète > Afb. 2 Voor' 'borende' kiespijn: Hahnemanns nux vomica - zeer giftig, maar onhomeomart.com)

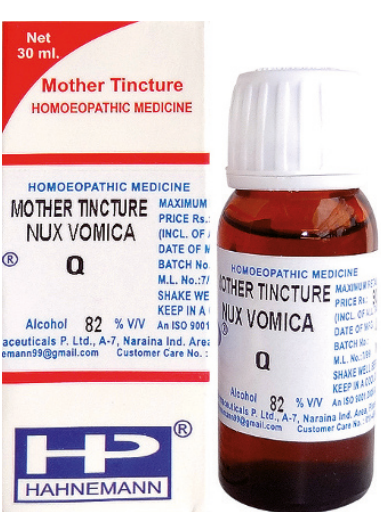


doorgaans het water flink. Zo werd in theorie de genezende werking van nux vomica op het water overgebracht, maar dan zonder de giftige neveneffecten.

Een zéér dubieuze overtuiging uiteraard, vooral in het kader van de moderne wetenschappen. Maar in één opzicht zou je kunnen zeggen dat Hahnemann met zijn concept van similia similibus curentur toch enigszins gelijk had.

\section{MELKBOERIN}

Hahnemanns Engelse tijdgenoot Edward Jenner leerde het medisch beroep bij een arts in zijn geboorteoord Gloucestershire. In 1770 ging de 21-jarige Jenner naar Londen om bij de beroemde arts-chirurg en natuurwetenschapper John Hunter te studeren, die ook pionier was in het transplanteren van tanden, en schrijver van de boeken 'A natural history of human teeth' en 'A practical treatise on diseases of the teeth'.

In die tijd vormde de pokken (variola) een enorme zorg. Daaraan gingen jaarlijks in Europa zo'n vierhonderdduizend mensen dood. De mortaliteit onder degenen die geïnfecteerd raakten varieerde van twee tot zes op de tien. Bij zuigelingen in Londen acht op de tien. Dr. Jenner was voor de pokken minstens gedeeltelijk immuun. Op 8-jarige leeftijd werd hij namelijk in Gloucester opzettelijk met de smetstof uit de laesies van een pokkenlijder geënt. De lijder was besmet met variola minor, een minder virulente en minder vaak voorkomende variant van de gevreesde variola major.
De techniek van infecteren door middel van krasjes op de huid, variolatie of inoculatie genoemd, was hier en daar al in verschillende werelddelen toegepast en werd recentelijk in Engeland geïntroduceerd. Maar die was lang niet zonder gevaar. Te veel van de geïnoculeerden werden daardoor toch ernstig ziek en stierven.

Jenner herinnerde zich hoe de melkboerinnen in Gloucestershire bekendstonden om hun mooie huid. Pokken kregen ze nooit. Wel koepokken (variola vaccinae), maar die ziekte was betrekkelijk goedaardig en liet ook geen littekens op hun gezichten achter. Jenner keerde terug naar zijn geboortestreek. Hij nam wat smetstof van een laesie van een met koepokken besmette melkboerin en bracht deze aan via krasjes in de huid van een 8-jarige jongen. Die werd ziek, maar niet ernstig. Vervolgens stelde Jenner de jongen aan de virulente pokken bloot - zonder reactie. Jenner voerde nog een paar proeven uit en publiceerde in 1798 een boekje over de techniek, die hij vaccinatie noemde.

Dit was dus het beginsel van similia similibus impediatur - iets wordt voorkomen door iets dat erop lijkt. (Die leus heb ik overigens zelf bedacht. FH)

\section{ZWART}

Hoe precies een vaccin iemand tegen pokken beschermt was Jenner onbekend. Maar de tweede helft van de negentiende eeuw werd een tijd van adembenemende vooruitgang in de geneeskunde. Zo lukte het Louis Pasteur met in zijn lab verzwakte pathogenen vaccins voor antrax en rabiës te ontwikkelen. (Hoewel alleen koepokken met koeien te maken had, werden de begrippen vaccineren en vaccinvan het Latijnse vacca, koe - gehanteerd.) Maar door de zeer gecompliceerde aard van de wisselwerking tussen het afweerstelsel en microben en virussen, hield het maken van een effectief vaccin meer in dan het inenten met een natuurlijke zwakke of een kunstmatig verzwakte variant van een gegeven pathogeen. Wel is het ons in deze coronatijd gelukt om binnen een jaar redelijk effectieve vaccins voor covid-19 te ontwikkelen. Maar voor (bijvoorbeeld) tbc, hiv/aids, malaria, syfilis? En een vaccin voor de cariës veroorzakende microbe Streptococcus mutans, dan? Dat daaraan al minstens een halve eeuw wordt gewerkt, weet ik uit deze amusante herinnering. Judd, een vriend van mij in een studentenflat waar ik in New York rond 1970 woonde, studeerde tandheelkunde. Hij vertelde me een keer hoe de docent tijdens een college mededeelde dat op dat moment een anticariesvaccin in ontwikkeling was. Judd en de andere studenten luisterden geschrokken. Maar, vertelde de docent geruststellend verder, het vaccin had een onprettige nevenwerking, het kleurde het tandvlees en de elementen geleidelijk aan zwart. De collegezaal barste uit in applaus. Ja, het uitboren en vullen van cariës was toen nog 'the bread and butter' van de gemiddelde tandarts.

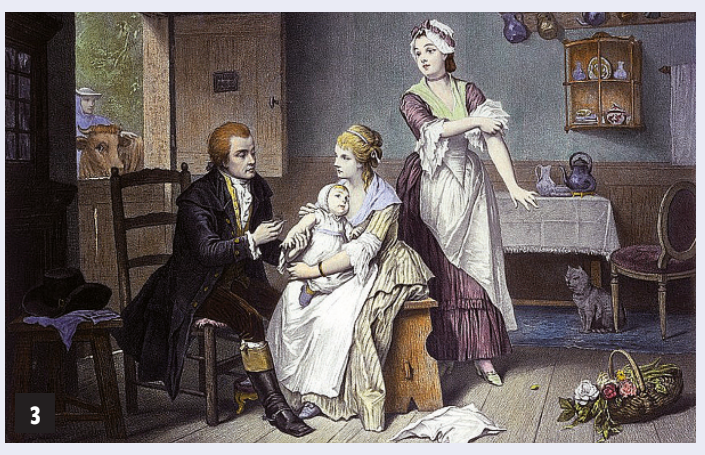

Afb. 3 Edward Jenner ent bij een kind de smetstof uit een koepokkenlaesie van een melkboerin. (Bron: Wellcome Collection)

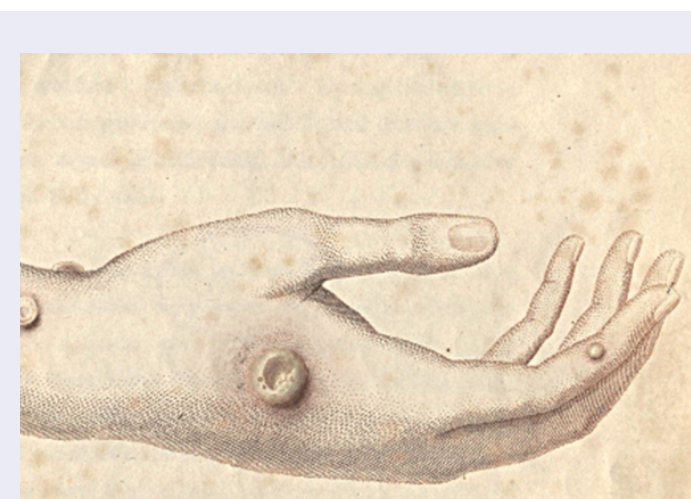

4 $\ll$ Afb. 4 Jenner liet zien hoe koepokken op de uiers door de handen van de melkboerinnen werden overgedragen. Maar van de onderliggende microben en virussen wist hij niets. (Bronnen: nyamcenterforhistory.org en Wellcome Collection) 